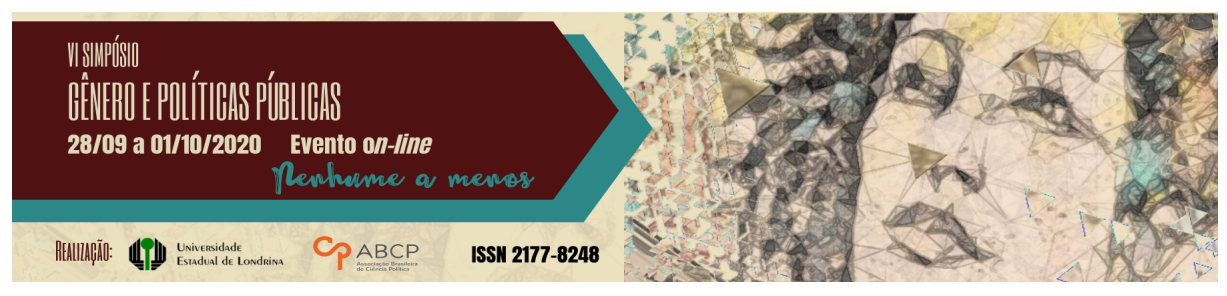

\title{
Saúde mental, Comunicação e Gênero: Oficinas Educativas e Atenção Psicossocial
}

\author{
Camila Viviane Lui de Sousa
}

\section{Resumo}

O foco desse artigo é apresentar os resultados da ação de extensão 'Saúde Mental, Comunicação e Gênero: Oficinas Educativas e Atenção Psicossocial'. A intervenção ocorreu com dez encontros, uma vez por semana, entre 03/09 e 20/11/2019, foi realizada no Centro de Atenção Psicossocial (CAPS II) de Foz de Iguaçu que atende população adulta com sofrimento mental grave. $\mathrm{O}$ método escolhido foram oficinas terapêutico-educativas em grupo, em que houve abordagem baseada na comunicação interpessoal com dinâmicas específicas e o uso de material de apoio escrito e audiovisual. Foram tratados temas da atualidade e relacionados às mulheres. De acordo com o observado nos encontros, as principais temáticas relacionadas com o adoecimento mental foram: corpo, trabalho, família e violência. Pela intervenção através das oficinas terapêuticas foi possível notar a importância de ações que levam em consideração o recorte de gênero.

Palavras-chave: saúde mental; gênero; oficinas

\begin{abstract}
The focus of this article is to present the results of the extension action 'Mental Health, Communication and Gender: Educational Workshops and Psychosocial Care'. The intervention took place with ten meetings, once a week, between September 3th and November 20th, 2019, it was held at the Psychosocial Care Center in Foz de Iguaçu, which serves the adult population with severe mental suffering. The method chosen was therapeuticeducational group workshops, in which there was an approach based on interpersonal communication with specific dynamics and the use of written and audiovisual support material. Current issues related to women were addressed. According to what was observed at the meetings, the main themes related to mental illness were: body, work, family and violence. Through

GT 06 - Gênero, cuidado e políticas de saúde
\end{abstract}


intervention through therapeutic workshops, it was possible to notice the importance of actions that take into account the gender focus.

Keywords: mental health; gender; workshops.

A escolha pela temática que liga gênero e saúde mental veio através da percepção, pela prática como trabalhadora da saúde mental desde 2012, das imbricações desses dois eixos. As mulheres são muito presentes como cuidadoras, principalmente nos estratos mais baixos e menos remunerados das profissões de cuidado, mas também como usuárias dos serviços de saúde. O que não é diferente dentro dos equipamentos de saúde mental e, assim, pelo interesse na temática de gênero e pela prática no campo da saúde foi observada a necessidade de aprofundar estes estudos.

O artigo aqui apresentado é parte da dissertação em andamento "Tristes, loucas ou más: Histórias de Vida de Mulheres em Sofrimento Mental" pela UNILA. Essa pesquisa é caracterizada como história de vida dentro de uma proposta operativa. Minayo (1992) descreve que a proposta operativa deve ter uma análise que contemple as comunicações individuais, que nesse trabalho se deu por meio de entrevistas; observações, que partiram das atividades grupais antes da realização das entrevistas com o projeto de extensão; informações sobre a instituição Centro de Atenção Psicossocial (CAPS II), a partir da legislação pertinente ao local do estudo, além de observações e levantamento bibliográfico relacionados ao tema.

Dessa forma, o foco é o trabalho de campo que se iniciou em setembro de 2019 com o desenvolvimento da ação de extensão 'Saúde Mental, Comunicação e Gênero: Oficinas Educativas e Atenção Psicossocial'

Esse trabalho traz diversos temas que em si são demasiados complexos, mas também estão imbricados: gênero, saúde mental e suas interlocuções com o trabalho, maternidade e violência. Porém, ainda são necessárias mais pesquisas sobre esse campo (ZANELLO, 
2017), assim, os objetivos da própria intervenção do projeto de extensão eram contribuir para a reflexão e um maior acolhimento e cuidado em saúde mental para as mulheres, assim como colaborar com as próprias usuárias do equipamento sobre seu processo de adoecimento e possíveis relações com a questão do gênero. Para compreender esse processo de cuidado hoje se faz necessário um resgaste do lugar social da loucura e sua relação com as mulheres.

\section{Gênero e loucura}

A relação com a loucura se transformou de acordo com cada período histórico. No Renascimento, por exemplo, estava ligada à percepção de transcendências, mas ao longo do século XVII, segundo Foucault, os loucos passaram a serem reconhecidos: "através de sua incapacidade para o trabalho e incapacidade de seguir vida coletiva" (FOUCAULT, 2013, p. 73).

Em fins do século XIX, com o advento da República no Brasil, houve um redimensionamento das políticas de controle social. Nesse contexto a loucura torna-se doença mental, monopólio da psiquiatria (ENGEL, 2000). Esse processo está contextualizado sob uma concepção de saúde como ausência de doença, com foco no biológico, individual que "passa a fragmentar o corpo em sistemas, órgãos, tecidos e células, estruturando um conhecimento cada vez mais especializado sobre cada função", chamado modelo biomédico (BATISTELLA, 2007, p. 54).

Segundo Zanello (2018), com a criação da clínica psiquiátrica nesse período é que o louco foi compreendido como um objeto com especificidade que deveria ser estudado e/ou tratado. Dessa forma foi transformado em "doente mental", separado de outros grupos marginais e excluído em asilos específicos, os manicômios. Assim, em um contexto de separação em sua especificidade de "alienado mental" o sujeito com transtorno mental foi silenciado, passou a não poder falar sobre si mesmo e a loucura foi objetivada como a não razão. 
Ao se dedicar ao estudo dos manicômios, Basaglia, precursor da reforma psiquiátrica italiana, afirma a necessidade do estudo "da relação entre o excluído e aquilo que o excluiu" (BASAGIA, 1985, p. 314) e diversas são as instituições com esses papéis, como a família, a escola, a fábrica e o manicômio, com finalidades e maneiras diferenciadas "a autoridade paterna é opressiva e arbitrária; a escola se baseia na ameaça e na vingança; o empregador explora o trabalhador; o manicômio destrói o doente mental" (BASAGLIA, 1985, p. 101).

Em meados do século XX, com a efervescência de uma série de movimentos sociais, se iniciam questionamentos sobre o papel das instituições, entre elas o Hospital Psiquiátrico e se volta cada vez mais para intervenções fora de seus muros (PASSOS et al, 2017).

Esse processo é chamado de Reforma Psiquiátrica e, apesar do termo em si ser contraditório e aparentemente indicar "transformações superficiais" prevaleceu com a finalidade de "construir consenso e apoio político" (AMARANTE 1995, p. 180). Após a Segunda Guerra se iniciaram experiências por diversos países como França, Inglaterra e Estados Unidos e, no caso brasileiro, muito influenciado pela experiência italiana, com um "viés desinstitucionalizante". Dessa forma, propunha o fim do manicômio e questionava o conjunto de saberes que o fundamentava (AMARANTE, 1995, p 195).

Em 1990, foi aprovada a Declaração de Caracas na Conferência da Organização Panamericana de Saúde, que orientava a Reestruturação da Assistência Psiquiátrica nas Américas, priorizando serviços comunitários e descentralizados, não mais um sistema hospitalar (OPAS, 1990). No Brasil, culminou com a Lei 10.216 de 2001 que versa sobre "a proteção e os direitos das pessoas portadoras de transtornos mentais e redireciona o modelo assistencial em saúde mental" (BRASIL, 2001).

Em consequência dessa lei, foi criada a portaria do Ministério da Saúde no 336, estabelecendo que os Centros de Atenção Psicossocial (CAPS) fossem organizados nas modalidades CAPS I, CAPS II e CAPS 
III, com estruturas físicas independentes dos hospitais, com um território e população de referência. O CAPS II, modalidade existente em Foz do Iguaçu, funciona em dois turnos, com atividades que podem incluir atendimentos individuais, em grupo, oficinas terapêuticas, visitas domiciliares, atendimento à família, além de atividades comunitárias que visam a inserção social do paciente. Ele tem como funções de responsabilização da rede de cuidados em saúde mental, supervisão de equipes de atenção básica, das unidades hospitalares, cadastramento dos pacientes que utilizam medicamentos de saúde mental no âmbito do seu território (BRASIL, 2002).

A partir desse processo se inicia a substituição de modelos de atenção, antes centrados na internação em hospitais para centrados nas comunidades, seus territórios e com equipamentos de saúde que propõem um olhar mais humanitário, cujo centro das ações é uma transformação cultural onde sejam construídos outros locais sociais para a loucura (ANDRADE, 2014). No entanto, esse processo não é uma mera modernização institucional e da psiquiatria: a luta antimanicomial está em um contexto das lutas sociais em que as explorações e opressões, como as de gênero, são compreendidas em sua relação com a loucura (PASSOS et al, 2017).

Heleieth Saffioti afirma:

O sexo é socialmente utilizado como referência para a construção da identidade de gênero, o que não significa que a matriz dominante de inteligibilidade do gênero não possa ser subvertida por matrizes não- hegemônicas, mas competidoras (SAFFIOTI, 1995, p. 159)

E essa construção da identidade de gênero está diretamente relacionada com outras categorias que constituem os sujeitos como raça/ etnia e classe (PASSOS et al, 2017).

Há uma série de estudos sobre as origens da dominação da mulher pelo homem, Beauvoir afirma que o homem: "só se pensa pensando o Outro (...) naturalmente sendo diferente do homem que se 
põe como o Mesmo é na categoria do Outro que a mulher é incluída" (BEAUVOIR, 2009, p. 108). Ao analisar a contribuição do materialismohistórico para pensar essa opressão, exemplifica com Engels que retrata como essa perspectiva traz intrínseca a ideia da emancipação da mulher ligada à emancipação econômica:

A opressão social que sofre é consequência de uma opressão econômica. A igualdade só se poderá restabelecer quando os dois sexos tiverem direitos juridicamente iguais, mas essa libertação exige a entrada de todo o sexo feminino na atividade pública (BEAUVOIR, 2009, p. 89).

Assim, a partir dessas perspectivas de gênero é possível lançar um outro olhar sobre a psiquiatria. Showalter destaca que chama a atenção de muitos teóricos a aliança entre a mulher e a loucura. Além das mulheres serem predominantes em números de casos, também são predominantemente representadas como irracionais e os homens como detentores da razão. A loucura em si é metaforicamente feminina e mesmo quando experienciada pelo homem sua representação é como uma doença de mulher (SHOWALTER, 1985).

Há estudos de prontuários do século XIX (ENGEL, 2000) em que foi observado que as razões dos acompanhamentos em Saúde Mental das mulheres eram diferentes das dos homens. Em relação às mulheres este acompanhamento se dava principalmente por questões relacionadas à sexualidade e, no caso dos homens, sobretudo por dificuldades com os papéis de trabalhador e provedor.

Dessa forma, observa-se a importância de um olhar específico para as mulheres e, a partir dos estudos epidemiológicos que levam em consideração a variável gênero, é reconhecida a necessidade de pesquisas que colaborem com a análise de como os papéis de gênero e os estereótipos sociais podem influenciar a expressão de saúde mental (ZANELLO, 2017).

É possível observar que os processos de subjetivação do que é ser homem e do que é ser mulher e os processos de adoecimento e do 
que significa estar adoecido mentalmente, atravessam diversas instituições e profissões, inclusive de cuidado (ANDRADE, 2014).

Por isso, pensar a questão de gênero no adoecimento possibilita a não manutenção dos estereótipos e lugares comuns das mulheres, que não colabora para a sua subjugação. A desconstrução da ideia de uma natureza feminina e a compreensão da singularidade que o processo saúde-doença tem para cada pessoa, pode contribuir para novas práticas de cuidado (ANDRADE, 2014).

\section{Oficinas educativas}

A ação de extensão denominada 'Saúde Mental, Comunicação e Gênero: Oficinas Educativas e Atenção Psicossocial', ocorreu com dez encontros, uma vez por semana, entre 03/09 e 20/11/2019. O trabalho de campo, assim, foi realizado no Centro de Atenção Psicossocial (CAPS II) de Foz de Iguaçu que atende população adulta com sofrimento mental grave.

O método escolhido foram oficinas terapêutico-educativas em grupo, em que houve abordagem baseada na comunicação interpessoal com dinâmicas específicas e o uso de material de apoio escrito e audiovisual. Foram tratados temas da atualidade e relacionados às mulheres, tais como: a violência de gênero, o trabalho feminino, corpo e pressões estéticas e cuidados com a saúde.

Os critérios para participar do grupo eram: ser mulher, ser utente/paciente do CAPS II e não ter grandes limitações cognitivas ou deficiência intelectual, pois alguns temas a serem tratados tinham algum grau de complexidade. As pacientes foram indicadas pelos profissionais da própria unidade.

A proposta metodológica do projeto baseou-se em práticas educativas que visam fortalecer o conhecimento, percebendo a saúde mental de forma integral e humanizada. Para a criação e desenvolvimento do projeto foi utilizada a pedagogia da educação 
popular proposta por Paulo Freire (2005), possibilitando a participação das usuárias do equipamento, a valorização do diálogo e o desenvolvimento da autonomia de todos(as) os(as) participantes.

A Tabela 1 apresenta como foram organizados os encontros das oficinas, desde sua idealização com a equipe até fechamento das atividades.

Tabela 1 - Apresentação dos encontros realizados

\begin{tabular}{|l|l|l|}
\hline Encontro 1 & $03 /$ set & $\begin{array}{l}\text { Conversa com equipe e coordenação: Apresentação do } \\
\text { projeto }\end{array}$ \\
\hline Encontro 2 & $10 /$ set & Participação de Atividade - Setembro Amarelo CVV \\
\hline Encontro 3 & $17 /$ set & $\begin{array}{l}\text { Roda de Conversa - O que é ser mulher na Sociedade } \\
\text { Atual }\end{array}$ \\
\hline Encontro 4 & $24 /$ set & Diferenças entre homens e Mulheres \\
\hline Encontro 5 & $01 /$ out & Autocuidado \\
\hline Encontro 6 & $08 /$ out & Pressão Estética e o Corpo \\
\hline Encontro 7 & $15 /$ out & Abordagem Fílmica - Filme: Absorvendo o Tabu \\
\hline Encontro 8 & $22 /$ out & Trabalho da Mulher e Trabalho Doméstico \\
\hline Encontro 9 & $29 /$ out & Roda de Conversa - Violência contra a Mulher \\
\hline Encontro 10 & $05 /$ nov & Finalização \\
\hline Encontro 11 & $20 /$ nov & $\begin{array}{l}\text { Com equipe do CAPSII, atividade realizada em } \\
\text { Abordagens em Saúde Mental }\end{array}$ \\
\hline
\end{tabular}

Fonte: Elaboração da Autora (2020)

Em 03/09/2019, foi realizada a primeira visita ao CAPS II, durante a qual houve a apresentação do projeto, com a participação da 
discente da UNILA (mestranda do IELA) e monitora e a coordenadora do projeto e docente responsável da UNILA (IELA). Na reunião estavam presentes a coordenadora e profissional da Terapia Ocupacional do CAPS II. Assim, foram apresentados os detalhes do Projeto de Extensão, seus objetivos, cronograma, temas e abordagem e a metodologia a ser utilizada.

Em 10/09/2019 houve a participação da monitora na Atividade do Setembro Amarelo. Nessa data foi realizada uma palestra do Centro de Valorização da Vida (CVV) de Foz do Iguaçu. No espaço organizado foi apresentada a importância da prevenção ao suicídio e um olhar para este ato como uma questão de Saúde Pública. Foi exposto o papel do CVV, um serviço gratuito, sem fins lucrativos, fundado em São Paulo em 1962.

Nesse espaço mais amplo foi o primeiro contato, por parte da monitora, com algumas das participantes das oficinas. Desse modo foi realizado o convite e apresentadas as temáticas a serem trabalhadas.

Em 17/09/2019 foi realizada uma roda de conversa sobre o tema: "O que é ser mulher nos dias atuais?" Participaram seis mulheres, mais a monitora da ação de extensão e a terapeuta ocupacional do equipamento em parte do grupo. As participantes tinham idades diversas, entre 30 e 59 anos, e não se obtiveram informações quanto ao diagnóstico de cada uma. No entanto, algumas delas relataram sofrer de tristeza, depressão e esquizofrenia. Em um primeiro momento nos apresentamos, dizendo o nome e o que mais gostamos em relação à cor, fruta e lazer.

Após este primeiro momento, foi apresentado o Projeto de Extensão e a relação com a UNILA; o que seria debatido em cada encontro e a proposta temática daquele dia. Para tanto, a atividade era buscar em revistas figuras de mulheres que representassem esse tema. De alguma forma, todas escolheram imagens que se relacionavam às suas histórias de vidas: mulheres com luvas de boxes, como lutadoras, mulheres com jaleco, mostrando a importância e intenção de 
manterem estudos, mulheres maquiadas e a vontade de terem mais cuidado consigo mesmas.

Uma senhora de meia idade, a mais velha do grupo, escolheu uma imagem de uma mulher com um cachorro, pela sua relação com animais - e de fato uma terapia que realiza com animais - com amigas. Falou sobre a importância de estar em um coletivo, socializar em espaços públicos, sobre atividade física e, por fim, como todos esses elementos colaboram para que ela esteja mais saudável.

Ao final, foram apresentadas algumas imagens com dados sobre as vivências tipicamente femininas, como assédio no transporte público, desigualdade salarial e se debateu que ser mulher nesse momento atual também é enfrentar essas disparidades, além de sofrimentos e adoecimentos.

Em 24/09/2019 foi realizado, em um primeiro momento, um resgate das atividades da semana anterior. Todas disseram que gostaram do encontro, principalmente por conseguirem falar sobre si mesmas.

A dinâmica desse novo encontro foi explicada: o uso do papel Kraft e o desenho de duas pessoas, a princípio sem detalhes de quem seria um homem e uma mulher. A primeira pergunta foi sobre as diferenças desde criança: - $\mathrm{O}$ que fazem as meninas e os meninos em relação ao brincar? - Quais são as suas diferenças de vestuário? Os pais criam de forma diferente filhos e filhas? A partir dessas questões, debateu-se e foram realizadas intervenções nas figuras para diferenciar homens e mulheres, não só pelas características físicas, mas também por ocupações e interesses.

As quatro participantes presentes falaram de suas experiências como meninas. Muitas delas tiveram pouco acesso ao brincar e aos brinquedos, faziam bonecas de sabugo de milho; suas infâncias transcorreram com muitas limitações, muitas cuidavam também da casa e dos irmãos mais novos. 
A partir dessas discussões foi realizada uma conexão desses contextos limitantes com o fato de, ao longo de suas vidas, elas terem tido pouco acesso ao estudo e ao lazer. Conversamos sobre algumas mudanças, tanto em relação aos homens quanto às mulheres no contexto atual, por exemplo: - como hoje as mulheres estão trabalhando em áreas hegemonicamente masculinas, mas também como essas mudanças em relação ao trabalho sobrecarregaram as mulheres, já que o trabalho doméstico foi acumulado junto às novas ocupações gerando uma dupla jornada e uma sobrecarga mental.

Em 01/10/2019 o tema da oficina foi o autocuidado.

Foram levantados fatos, situações e contexto que as estressavam, questões negativas em seus cotidianos, mas também, o que é positivo e que colabora para amenizar ou lidar com as situaçõesproblema levantadas.

A partir dessa proposta as cinco participantes trouxeram questões de suas vidas. Uma delas relatou como as medicações interferem no seu cotidiano, com os efeitos colaterais, e também como o celular a incomoda, principalmente quando está tentando dormir. Mais de uma participante concordou com o que foi dito sobre as medicações. Além disso, outra relatou que tem falta de ânimo para realizar atividades, mesmo quando se programa para realizá-las, isso também afeta seu apetite e deixa de comer.

Algo que foi possível observar - e que praticamente todas elas relataram -, foi sobre os relacionamentos familiares, os conflitos diretos com noras, maridos e a sobrecarga no cuidado com os netos, por exemplo.

Uma participante em específico falou do conflito com o marido e como a vida ativa que ela tem hoje - e fora da esfera doméstica - o incomoda. Disse que se sentia cobrada em ser somente uma dona de casa e que não queria isso e nem se identificava com esse papel.

Os pontos positivos nos seus cotidianos são: atividades físicas, 
como dançar, ir à academia, trabalho com horta, desligar o celular, sair, conversar com as pessoas, brincar com animais, dormir, aula de pintura, igreja e citaram equipamentos públicos como o próprio CAPSII e o CRAM (Centro Referência em Atendimento à Mulher em Situação de Violência). As próprias participantes notaram que, em relação aos aspectos no seu cotidiano existiam mais itens positivos do que negativos. Nesse sentido, foi debatido como esses aspectos positivos fazem parte do autocuidado. Esse dia foi finalizado com uma atividade de alongamento e respiração.

Em 08/10/2019 houve a participação de seis mulheres e foi trabalhado o tema da pressão estética. O grupo foi iniciado com a seguinte dinâmica: - foi utilizada uma bolsinha e falou-se que nela havia uma imagem de uma mulher e que todas deveriam descrever as qualidades positivas tanto físicas quanto de personalidade dessa pessoa. O que havia, na realidade era um espelho! Algumas se surpreenderam e sentiram dificuldade em falar sobre qualidades físicas, dizendo apenas: "essa pessoa já foi bonita", mas conseguiram desenvolver mais sobre as qualidades de personalidade, no geral se viam como caridosas, cuidadosas com outros, sensíveis. Foi debatido como a imagem na mídia expressa muitas vezes um ideal de beleza que não existe. Uma das participantes, a mais jovem do grupo, relatou ter um adoecimento relacionado diretamente com a questão do corpo: anorexia e bulimia. Disse que, por muito tempo, sofreu por ter sobrepeso e, por isso, desenvolveu transtorno alimentar, mas estava estável naquele momento.

Em 15/10/2019 foi projetado o filme: "Absorvendo o Tabu" sobre mulheres na Índia que começaram um negócio próprio vendendo absorventes. O "tabu" que nomeia o filme é sobre a menstruação, tema muitas vezes não debatido, nem mesmo entre as mulheres. Esse tema foi importante para introduzir questões sobre como alguns processos naturais em relação ao corpo da mulher podem ser considerados como tabu, o que dificulta, por exemplo, o acesso a informações que poderiam colaborar com a mulher no seu processo de 
cuidado.

Em 22/10/19, para debater Trabalho Doméstico e Trabalho da mulher como um todo, foi passado um capítulo da série "Nossa voz ecoa" que falava especificamente sobre mulheres que já haviam trabalhado como domésticas, em sua maioria negras.

Três das cinco participantes já tinham exercido essa função. Muitas delas falaram dos maus tratos por parte dos patrões. Uma das mulheres, em específico, foi para outro Estado para trabalhar como doméstica e morar com uma família quando tinha apenas 13 anos de idade. Esse processo para ela também foi compreendido como uma emancipação financeira e da família. Todas as utentes/pacientes que participaram nessa data falaram que já tiveram trabalhos relacionados ao cuidado, ensino ou com tarefas de organização, como babá, professoras, secretárias e recepcionistas. Todas comentaram a respeito da sobrecarga de trabalho, pois além de seu trabalho fora da residência também trabalhavam em suas casas, referenciando, assim, as duplas jornadas de trabalho. Nenhuma estava ativa, por conta do adoecimento mental, duas delas estavam afastadas de seus trabalhos com aposentadoria, outras duas desempregadas sem receber nenhum tipo de auxílio.

Em 29/10 / 19 foi tratado o tema da violência contra a mulher. Foi apresentada uma história fictícia de uma jovem que gostava de sair para dançar, conheceu um moço e começaram a namorar. A partir de então ele começou a querer controlar sua roupa, a afastá-la de amigos e família. Algumas perguntas nortearam a conversa:

- O que pode ser considerado sinal de uma relação abusiva no caso apresentado?

- O que distingue esse tipo de relação de uma relação saudável?

- Em sua família se conversava sobre relações amorosas?

- Você já vivenciou uma relação abusiva?

Todas concordaram que os sinais de relação abusiva na história 
começaram a aparecer assim que o namorado quis restringir os tipos de roupa de sua namorada e as relações sociais dela. As participantes disseram que relações saudáveis são aquelas que envolvem respeito e cuidado recíproco. Todas falaram de experiências de relações abusivas, sendo que algumas delas se separaram por conta disso e outras disseram que tentaram permanecer na relação, mas sempre com a condição de mudanças de seus parceiros.

Após esta etapa foram relatadas as diversas formas de violência, que não são só físicas, mas também psicológicas, patrimonial, doméstica e sexual. Nessa data compareceram quatro participantes, sendo que duas falaram ter sofrido violência sexual, uma por parte do padrasto e outra dentro de seu casamento.

A escolha dessa temática por último foi intencional, já que foi priorizado a construção de relações de confiança nesse processo, para que as participantes se sentissem à vontade e confiantes de apresentarem as situações de vulnerabilidades que vivenciaram. De fato, a avaliação é que essa escolha foi acertada pela densidade de relatos de experiências dessas mulheres. Infelizmente, todas já haviam passado por algum tipo de violência, principalmente dentro das relações íntimas.

Em 5/11/2019 foi a finalização das oficinas. Nessa data conversamos sobre todas as oficinas, fizemos uma retrospectiva. No geral, todas as participantes gostaram da metodologia do trabalho, citaram especificamente a importância de realizar atividades diferentes para tratar os temas, como as dinâmicas, fazer desenhos, utilizar revistas, filmes, entre outros. Indicaram que gostariam que as oficinas continuassem e, diante dessa demanda, foi realizado o compromisso de assar a reivindicação para equipe do CAPS II.

Em relação ao tratamento do tema sobre as mulheres, relataram que foi importante para elas; algumas passaram a notar e refletir sobre situações e temas de modo diferente, como o trabalho doméstico e as diferenças de gênero. 
De acordo com o observado nos encontros, as principais temáticas relacionadas com o adoecimento mental foram: corpo, trabalho, família e violência. Essas temáticas também estiveram presentes nas entrevistas.

\section{Considerações finais}

As participantes das oficinas relataram que foi um espaço importante para elas, algumas passaram a notar e refletir sobre situações e temas de modo diferente, principalmente sobre a sobrecarga de trabalho e as diferenças de gênero.

De acordo com o observado nos encontros, as principais temáticas relacionadas com o adoecimento mental foram: corpo, trabalho e violência. Pela intervenção através das oficinas terapêuticas foi possível notar a importância de ações que levam em consideração o recorte de gênero. Há perspectivas em saúde que têm o foco no biológico, compreendem que as mudanças hormonais poderiam, por exemplo, tornar as mulheres mais propícias a desenvolver transtornos mentais. Essa visão desconsidera que o sofrimento humano tem diversas faces e que as construções históricas das relações de gênero, por exemplo, podem colaborar com o sofrimento da mulher.

Sobre a questão do corpo, esse é o local das ambiguidades dos sujeitos humanos e espaço por excelência da loucura. O corpo feminino e principalmente, a sexualidade feminina inspiraram grande temor dos médicos e alienistas. Dessa forma, constitui-se em alvo prioritário das intervenções normalizadoras da medicina e psiquiatria (ZANELLO, 2018). No entanto, para medicar ou normalizar esse corpo é necessário diagnosticá-lo.

Na história da Psiquiatria em específico, da Psicanálise, os estudos sobre as mulheres histéricas são famosos. Freud, em seu estudo sobre o caso Dora, assim define a histeria:

Eu consideraria histérica, sem hesitar, toda pessoa, quer ela seja 
capaz de gerar sintomas somáticos ou não, em quem uma ocasião de excitação sexual produz sensações desprazerosas de maneira predominante ou exclusiva (FREUD, 2019, p. 67)

Apesar de considerar histérica toda a pessoa com esse padrão de comportamento, é possível visualizar que há predominantemente em seus estudos mais casos clínicos femininos do que masculinos.

Em 1952, influenciada pela psicanálise, a Associação Americana de Psiquiatria, lançou um manual para sistematizar e organizar terminologias associadas aos transtornos mentais, o chamado Manual Diagnóstico e Estatístico de Transtornos Mentais (DSM). Em sua primeira edição tinha 106 categorias, a última edição de 2013 o DSM-V tem mais de 330 categoriais de classificação de transtornos. Há muitas críticas sobre seu uso, principalmente em relação às atualizações, pois transforma o sofrimento psíquico em patologias de cunho cerebral (MARTINHAGO et al, 2019).

Para classificar um determinado transtorno mental, os sujeitos têm que ter um certo número de sintomas, mas existem algumas limitações: a primeira delas é a criação dos sintomas. Por exemplo: o choro é relacionado à tristeza, só que desde crianças os homens são incentivados a não demonstrar fraqueza, não chorar, mas isso não quer dizer que não sintam tristeza. A segunda limitação é sobre o que é o sintoma, que muitas vezes pode estar relacionado e enquadrado nos valores de gênero, por exemplo, quando a mulher deixa de cuidar da casa. Por fim, são os valores do médico quando enquadram as queixas em sintomas (ZANELLO, 2018).

O próprio processo de diagnóstico não é desprovido de estereótipos de gênero. As diversas demandas das mulheres, como precarização do trabalho, duplas jornadas, violência doméstica, entre outras, são transformadas pela racionalidade biomédica em sintomas ao buscar um olhar sobre a natureza, o que denota, assim, uma visão biologizante do sofrimento feminino (ANDRADE, 2014).

Uma possível consequência desses olhares seria a 
hiperdiagnosticação das mulheres e um não olhar para os sofrimentos dos homens. É possível que isso ocorra em relação à depressão, tido como predominantemente feminina (ZANELLO et al, 2014).

Essa hiperdiagnosticação, também pode levar a uma hipermedicalização das mulheres (ZANELLO 2014). Uma vez que elas são predominantes nos serviços de saúde mental e as maiores usuárias de medicamentos psicotrópicos. Por trás dessa visão há uma concepção de vulnerabilidade que faz parte da natureza feminina e, dessa forma, seus sofrimentos mentais também teriam essa origem (ANDRADE, 2014).

Outra conexão é entre raça e adoecimento mental. Fanon relaciona diretamente os sofrimentos mentais com os processos coloniais e de opressão racial: "a guerra de liberação nacional que o povo argelino vem conduzindo há sete anos [...] tornou-se um terreno favorável ao aparecimento de transtornos mentais" (FANON, 1968, p. 213).

Sobre o trabalho uma das principais queixas era a sobrecarga pelo trabalho doméstico e o público. A falta da distribuição dessas tarefas seja dentro do próprio núcleo familiar, seja por falta de políticas de Estado, impacta na educação e na inserção laboral das mulheres, já que o "día tiene 24 horas para ambos sexos" (FERRO, 2019, p. 128). Através de Sistemas Públicos de Cuidados, seria possível incentivar a redistribuição dessas tarefas (FERRO, 2019). Dessa forma, a defesa da divisão de tarefas nessa esfera, implica não somente: “Tornar o trabalho de cuidados visível; é preciso redistribuí-lo entre o Estado, empresas privadas, organizações da sociedade civil e entre homens e mulheres" (DUPONT, 2019. p. 185).

Há possibilidades desde a educação infantil do ensino da importância do cuidado e sua necessária divisão entre os gêneros, desde políticas de licenças igualitárias entre pais e mães para cuidar dos filhos (DUPONT, 2019). Além de outras reivindicações históricas do movimento feminista como creches, restaurantes e lavanderias 
comunitárias.

A partir do que foi observado em campo foi possível notar como as mulheres usuárias dos equipamentos de saúde mental tinham um histórico amplo com as questões da violência, seja ela psicológica, moral física ou sexual. A maior parte dessas mulheres sofreu violência no espaço doméstico, pelo marido, padrasto ou pessoas próximas às famílias que frequentavam a casa.

A questão da violência faz parte da expressão da desigualdade de gênero e é um dos atos considerados mais cruéis e de violação aos Direitos Humanos. Por dia, no Brasil, morrem dez mulheres vítimas de violência, sendo assim, também é considerado uma questão de Saúde Pública (TEDESCHI et al, 2014).

Desse modo, é possível compreender que o sofrimento mental também pode ser analisado a partir das histórias de vida das mulheres. Nesse enquadramento específico todas as mulheres que participaram da pesquisa já haviam passado por instituições especializadas, como hospitais e centros de atenção psicossocial (CAPS). Assim, estavam diagnosticadas, medicadas e, de certa forma, marcadas por procedimentos ligados à saúde que, muitas vezes, procuram respostas biológicas para processos sociais. Não se descarta aqui nenhum desses aspectos e/ou diferentes abordagens de cuidado, mas se considera de máxima importância a escuta qualificada das pessoas que vivenciam o sofrimento mental de forma intensa e, frequentemente por um período prolongado de tempo.

Assim, as relações entre gênero e saúde mental são possíveis de serem analisadas já que em diversas populações que passam pelo sofrimento mental, esses processos têm relação com o fato de serem mulheres. Assim, é observável que a depressão, ansiedade, fobias, entre outros estão ligadas também às relações sociais de opressão e diferenciações humana. 


\section{Referências}

ANDRADE, A. P. (Entre) Laçamentos possíveis entre gênero e saúde mental. In: Zanello, V. Andrade, A. P. Saúde Mental e gênero: diálogos práticas e interdisciplinaridade, Curitiba: Appris, 2014.

BASAGLIA, F. As Instituições da Violência. In Basaglia, et al. A. Instituição Negada: Relato de um Hospital Psiquiátrico. Rio de. Janeiro: Graal, 1985.

BATISTELLA, Carlos. Abordagens contemporâneas do conceito de saúde. In: FONSECA, Angélica Ferreira; CORBO, Ana Maria D'Andrea (Org.). O território e o processo saúde- doença. Rio de Janeiro: EPSJV/FIOCRUZ, 2007. (Coleção Educação Profissional e Docência em saúde: a formação e o trabalho do agente comunitário de saúde, 1). p. 51-86

BEAUVOIR, S. O Segundo Sexo. Rio de Janeiro: Nova Fronteira. 2. Edição, 2009.

BRASIL. Lei 10216 de 6 de abril 2001. Dispõe sobre a proteção e os direitos das pessoas portadoras de transtornos mentais e redireciona o modelo assistencial em saúde mental. Ministério da Saúde.

DUPONT, S. A necessidade de políticas públicas para a redistribuição do cuidado. Mulheres entre fronteiras: olhares interdisciplinares desde o sul. Silvia Lilian Ferro e Thaíse Vieira Thomé (Org.) - Fos do Iguaçu (PR): EDUNILA, 2019. p. 172-195

ENGEL, Magali. Psiquiatria e feminilidade. In: PRIORE, Mary Del (Org.). História da Mulheres no Brasil. $3^{a}$ ed. São Paulo: Contexto, 2000.

FANON, F. Os condenados da terra. Ed. Civilização Brasileira, Rio de Janeiro. 1968.

FERRO, S. Aportes de la Economía del Cuidado para um sistema público de cuidados em América Latina. Mulheres entre fronteiras: olhares interdisciplinares desde o sul. Silvia Lilian Ferro e Thaíse Vieira Thomé (orgs) - Fos do Iguaçu (PR): EDUNILA, 2019, p. 100145.

FOUCAULT, M. História da Loucura na Idade Clássica. São Paulo: Perscpectiva, 2013.

FREIRE, Paulo. Pedagogia do oprimido: saberes necessários à prática 
educativa. São Paulo: Paz e Terra; 2005.

FREUD, S. Fragmento de uma análise de histeria: [o caso Dora]. Porto Alegre: L\&PM, 2019.

MARTINHAGO, F., CAPONI, S. Controvérsias sobre o uso do DSM para diagnósticos de transtornos mentais. Physis: Revista de Saúde Coletiva, Rio de Janeiro, v. 29, n. 2, e290213, p. 01-19, 2019.

MINAYO, M. O desafio do conhecimento: pesquisa qualitativa em saúde. Rio de Janeiro- São Paulo, ABRASCO-HUCITEC, 1992.

PASSOS, R. G. PEREIRA, M. de O. Luta Antimanicomial, Feminismos e Intersecionalidades: Notas para debate. Luta antimanicomial $e$ feminismos: discussões de gênero, raça e classe para a reforma psiquiátrica brasileira. 1 ed. Rio de Janeiro: Autografia, p. 25-51, 2017.

SAFFIOTI, H. Diferença ou indiferença: gênero, raça/etnia, classe social. In: ADORNO, Sergio (Org.). A sociologia entre a modernidade e a contemporaneidade. Porto Alegre: UFGRS, 1995.

SHOWALTER, E. The female Maladay-Women, Madness and English Culture 1930- 1980. London Pantheon Books. 1985

TEDESCHI, L. A., COLLING, A. M. Os direitos humanos e as questões de gênero. Hist. R., Goiânia, v. 19, n. 3, 2014.

ZANELLO, $\mathrm{V}$ et al. Uma história do silêncio sobre gênero e loucura Parte I Sobre o que não se fala em uma arqueologia do silencia: as mulheres em história da loucura. Saúde Mental e Gênero: Diálogos, Práticas e Interdisciplinaridaes. Curitiba: Appris. p. 17-28, 2014

ZANELLO, V. Saúde Mental, gênero e dispositivos. Cultura e processos de subjetivação. 1. ed. Curitiba: Appris, 2018.

ZANELLO, V. Saúde Mental, Gênero e Interseccionalidades. In: PEREIRA, M. de O.; PASSOS, R. G. (Org.). Luta antimanicomial e feminismos: discussões de gênero, raça e classe para a reforma psiquiátrica brasileira. 1 ed. Rio de Janeiro: Autografia, 2017. p. 5269. 